\title{
Ambientes Virtuais de Aprendizagem e o ensino de Design
}

\section{Virtual Learning Environment and Design teaching}

\author{
CARVALHO, Alecir Francisco de; Doutor em Design; UEMG \\ alecircarvalho@gmail.com \\ FARBIARZ, Jackeline Lima; Doutora em Educação e Linguagem; PUC-Rio \\ jackeline@puc-rio.br \\ FARBIARZ, Alexandre; Doutor em Design; UFF \\ alexandre.farbiarz@gmail.com
}

\section{Resumo}

O objetivo deste artigo é identificar e analisar os Ambientes Virtuais de Aprendizagem utilizados em universidades nacionais e internacionais que ofertam cursos de Design. Foi realizado um levantamento dos AVAs utilizados por diferentes instituições em propostas de Educação a Distância. Apresentaremos as escolhas e opções assumidas pelas instituições de ensino de Design acerca dos Ambientes Virtuais de Aprendizagem. Nosso intento é avaliar como o campo do Design "observa" ou se "relaciona" com a Educação a Distância, de modo particular com os Ambientes Virtuais de Aprendizagem. Nesta pesquisa foram analisados quatro rankings de entidades internacionais para, em seguida, ser selecionado o mais apropriado. Foi possível identificar a partir dessa análise do panorama atual um grau de isolamento entre o Design e a Educação a Distância na proposição da diversidade de construção de novos AVAs.

Palavras-chave: Design e Educação a distância; Ambientes Virtuais de Aprendizagem; Significados e Sentidos em AVAs.

\begin{abstract}
The objective of this article is to identify and analyze the Virtual Learning Environments used in national and international universities that offer Design courses. A survey of AVAs used by different institutions was carried out in distance education proposals. We will present the choices and options assumed by Design education institutions about Virtual Learning Environments. Our aim is to evaluate how the field of Design "observes" or "relates" to Distance Education, particularly with Virtual Learning Environments. In this research were analyzed four rankings of international entities to then be selected the most appropriate. It was possible to identify from this analysis of the current panorama a degree of isolation between Design and Distance Education in proposing the diversity of construction of new AVAs.
\end{abstract}

Keywords: Design and Distance Education; Virtual Learning Environments; Meanings and Senses in AVAs. 


\section{Interseções entre Design e Educação}

$\mathrm{Na}$ atualidade é possível encontrar diferentes pesquisas direcionadas à interseção entre Design e Educação. Podemos citar os estudos promovidos por Portugal (2013) e Couto \& Oliveira (1999), dedicados a analisar as contribuições do campo do Design na elaboração de livros didáticos, jogos, softwares, entre outros suportes educativos. É oportuno reconhecer a importância e a oportunidade de contar com a participação de designers, na concepção de tais suportes com o intuito de favorecer tais construções de forma interdisciplinar e colaborativa.

Nessa direção, é possível também citar as contribuições de Pereira; Gonçalves (2004) empenhadas na estruturação de um ambiente de aprendizagem online colaborativo para o ensino no âmbito da Arquitetura e do Design. Assim, parte-se do pressuposto de que o Design pode contribuir para o aprimoramento de inúmeros objetos e serviços em diferentes segmentos da sociedade, entre esses no campo da Educação à Distância. Podemos considerar que o Design é capaz de favorecer processos de interação entre sujeitos, objetos e conteúdos em situações de ensinoaprendizagem.

O objetivo deste artigo é identificar e analisar os Ambientes Virtuais de Aprendizagem utilizados em universidades nacionais e internacionais que ofertam cursos de Design. Para tanto, foi realizado um levantamento dos AVAs utilizados por diferentes instituições em propostas de Educação a Distância. Apresentaremos as escolhas e opções assumidas pelas instituições de ensino de Design acerca dos Ambientes Virtuais de Aprendizagem. Nosso intento é avaliar como o campo do Design "observa" ou se "relaciona" com a Educação a Distância, de modo particular com os Ambientes Virtuais de Aprendizagem. Iniciaremos a partir daqui uma verificação do ponto de vista institucionalizado do campo do Design.

Inicialmente nos dedicamos apenas às faculdades e universidades que ofertam cursos de Design na modalidade a distância. Posteriormente, nos voltamos para as faculdades e universidades que ofertam, entre outros cursos, o curso de Design mesmo que apenas na modalidade presencial. Neste segundo caso buscaremos os AVAs utilizados para a oferta de cursos de um modo geral. Para essa seleção foram considerados os seguintes critérios: a) o ranking promovido por entidades renomadas, b) instituições que possuem iniciativas em EaD e em Design, c) o acesso a essas iniciativas das instituições para a promoção da análise, d) possibilidade de mapeamento dessas iniciativas de modo a contribuir para esta pesquisa.

A utilização de critérios de ranking teve como finalidade servir apenas como uma delimitação adequada (recorte) da pesquisa. Sabe-se que os rankings de instituições carregam ideologias, contradições e circunscrevem-se em diversos interesses, tais como econômicos, políticos, entre outros. Assim, verificamos os rankings existentes, aplicados internacionalmente na classificação das instituições de ensino. Durante a verificação, percebemos a existência de diferentes critérios adotados na avaliação das faculdades e universidades. Também observamos os riscos de inclinação dos rankings aos diversos interesses que poderiam estar implícitos nessas classificações.

Analisamos quatro rankings de entidades internacionais para, em seguida, selecionarmos o mais apropriado. São eles: Red Dot Design; QS World University; Bloomberg Businessweek e o Businessinsider. Após uma análise desses quatro modelos, observamos que as classificações do Bloomberg Businessweek e do BusinessInsider seguem critérios direcionados a interesses essencialmente de mercado e de negócios, desfavorecendo uma análise de cunho qualitativamente acadêmico. 
Assim, optamos por utilizar o modelo de classificação Red Dot Design, concebido essencialmente na análise de cursos de Design, e o modelo QS World University, que avalia variadas instituições de ensino superior. A escolha desses dois rankings foi assim definida também pelo fato de adotarem como critérios de classificação aspectos associados ou correlacionados a ensino, pesquisa e extensão.

\subsection{Ambientes Virtuais de Aprendizagem e a classificação Red Dot Design}

A classificação do Red Dot Design é específica de universidades internacionais que ofertam cursos de Design. Em seus critérios de classificação, consideram a avaliação por empresas, escritórios da área e profissionais designers atuantes no mercado. O Red Dot Design acompanha e avalia a qualificação de uma instituição pela produção de novos conceitos de Design ao longo de um período de tempo.

As avaliações e classificações das universidades feitas pelo Red Dot Design são categorizadas em dois grupos de instituições: um com universidades localizadas na região da Ásia-Pacífico, englobando grande parte da Ásia Oriental, sul da Ásia, sudeste da Ásia e Oceania, e outro grupo de universidades sediadas nos continentes da América e Europa.

Neste estudo, fizemos a opção por analisar apenas as classificações do grupo América e Europa. Utilizamos nesta pesquisa a classificação das instituições de ensino de Design considerando os resultados das edições Red Dot Design nos anos de 2014 a 2017. Compilamos as classificações do período mencionado no quadro a seguir:

Quadro 1 - Compilação da classificação hierárquica vertical descendente de instituições de ensino superior de Design

\begin{tabular}{|c|c|c|c|c|c|}
\hline \multicolumn{4}{|c|}{$\begin{array}{l}\text { Classificação } \\
\text { conforme o ano }\end{array}$} & \multirow[t]{2}{*}{ Instituição } & \multirow[t]{2}{*}{ País } \\
\hline 离 & กุ & $\stackrel{0}{\circ}$ & $\stackrel{ }{\circ}$ & & \\
\hline 10 & 20 & 1 은 & 10 & Umeå Institute of Design | Umeå University & Suécia \\
\hline $2 \underline{0}$ & 10 & 3은 & 40 & Art Center College of Design & EUA \\
\hline 30 & 3은 & 20 & 30 & ENSCI - Les Ateliers & França \\
\hline 80 & 4은 & 4은 & $2 \underline{0}$ & Savannah College of Art and Design & EUA \\
\hline $4 \underline{0}$ & 6은 & 60 & 60 & Academy of Art University & EUA \\
\hline 70 & 5은 & 50 & 50 & Middle East Technical University (METU) & Turquia \\
\hline 50 & 80 & 90 & ---- & California College of the Arts & EUA \\
\hline 10 은 & 70 & 80 & ---- & Burg Giebichenstein University of Art and Design & Alemanha \\
\hline ---- & 13 은 & 70 & 130 & Royal College of Art (RCA) & Inglaterra \\
\hline 6o & ---- & 150 & 140 & The Oslo School of Architecture and Design (AHO) & Noruega \\
\hline ---- & ---- & 100 & 110 & University for the Creative Arts & Inglaterra \\
\hline ---- & 90 & $12 \circ$ & ---- & Emily Carr University of Art and Design & Canadá \\
\hline ---- & ---- & 110 & 120 & Berlin Weissensee School of Art & Alemanha \\
\hline
\end{tabular}




\begin{tabular}{|c|c|c|c|c|c|}
\hline \multicolumn{4}{|c|}{$\begin{array}{l}\text { Classificação } \\
\text { conforme o ano }\end{array}$} & \multirow[t]{2}{*}{ Instituição } & \multirow[t]{2}{*}{ País } \\
\hline 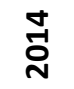 & חั & O্் & 㑼 & & \\
\hline---- & 10 은 & 13 은 & ---- & University of Applied Arts Vienna & Áustria \\
\hline 110 & 140 & ---- & ---- & Pratt Institute & EUA \\
\hline---- & $12^{\circ}$ & 140 & ---- & Pontifical Catholic University of Rio de Janeiro & Brasil \\
\hline--- & ---- & --- & 70 & University of Montreal & Canadá \\
\hline---- & ---- & ---- & 80 & Central Saint Martins College of Art \& Design & Inglaterra \\
\hline---- & --- & --- & 90 & Massachusetts Institute of Technology & EUA \\
\hline---- & --- & ---- & 10 은 & Shenkar College of Engineering, Design and Art & Israel \\
\hline---- & ---- & ---- & 15 운 & Rhode Island School of Design (RSID) & EUA \\
\hline---- & 11 은 & --- & ---- & Tomas Bata University in Zlín (TBU) & R. Tcheca \\
\hline---- & 150 & --- & ---- & Darmstadt University of Applied Sciences (H_DA) & Alemanha \\
\hline 90 & ---- & ---- & ---- & Ravensburg University of Cooperative Education & Alemanha \\
\hline $12 \circ$ & --- & --- & --- & University of Applied Sciences Northwestern Switzerland & Suíça \\
\hline 13 운 & --- & ---- & --- & Folkwang University of the Arts & Alemanha \\
\hline $14 ㅇ$ & ---- & --- & ---- & Coventry University & Inglaterra \\
\hline 15 운 & --- & --- & --- & University of Houston & EUA \\
\hline
\end{tabular}

Fonte: Red Dot Design (edições 2014 a 2017).

Na elaboração do Quadro 1, utilizamos a compilação da classificação Red Dot Design referente às edições dos anos de 2014 a 2017, prevalecendo, em alguns casos, o sequenciamento da classificação mais recente (2017), quando ocorre, por exemplo, a coincidência na ordenação.

Em uma análise preliminar dessa classificação, é possível notar que, entre as 28 instituições que aparecem, 8 são universidades sediadas nos Estados Unidos, 5 na Alemanha e 4 na Inglaterra. Na América Latina, observamos apenas a presença da Pontifícia Universidade Católica do Rio de Janeiro (PUC-Rio), ocupando a 12a e 14a posições nas edições de 2015 e 2016, respectivamente. A partir desse espectro, é possível notar um predomínio no ranking de instituições situadas no hemisfério norte-americano e em países de economia mais consolidada na Europa. Assim, sugerem fatores de hegemonia econômica como um reflexo da alocação de universidades dedicadas ao ensino de Design.

Para fins de análise nesta pesquisa, foram realizadas buscas sistemáticas nos sites das instituições classificadas no Red Dot Design, com o intuito de levantar informações referentes aos seguintes aspectos: a) presença de cursos de Design na modalidade a distância; b) nome do curso de Design na modalidade EaD; c) nível de formação; d) duração em meses ou anos; e) carga horária do curso; f) nome do Ambiente Virtual de Aprendizagem utilizado para o ensino de Design; g) qualificação ou nível de formação do curso; h) se há cursos na modalidade a distância que não são 
de Design. Além disso, também se buscou verificar informações adicionais divulgadas nos sites que pudessem contribuir para o desenvolvimento dessa investigação.

As três primeiras instituições do Quadro 1: Umeå Institute of Design; Art Center College of Design e ENSCl - Les Ateliers, localizadas, respectivamente, na Suécia, nos Estados Unidos e na França, não oferecem na modalidade a distância cursos de Design ou outro curso de graduação ou pós-graduação. Já a Universidade Savannah College of Art and Design oferece disciplinas na modalidade a distância utilizando o Ambiente Virtual de Aprendizagem Blackboard. Entre os cursos oferecidos online por essa instituição, estão os de Design Gráfico, Design de Interior, Gestão do Design, Design de Animação, entre outros. Tais cursos estão qualificados em nível de formação da graduação à pós-graduação

A Academy of Art University oferece desde 2002 vários cursos online utilizando o recurso virtual intitulado "LMS Whiteboard". As qualificações dos cursos online vão desde aqueles que antecedem a graduação até os de pós-graduação. As áreas em que a Universidade oferece os cursos são no âmbito tanto do Design como das áreas de Publicidade e Arquitetura, entre outras no universo das Artes. A Instituição denomina o seu ambiente Learning Management System (LMS) Sistema de Gestão de Aprendizagem (LMS) - "[...] uma ferramenta web centralizada que permite facilmente educandos e educadores interagirem por meio de trocas digitais personalizadas".

A Universidade alocada na sexta posição em nossa compilação da classificação, Middle East Technical University (METU), utiliza o Moodle para a oferta de seus cursos online, intitulado "ODTUClass". Esses cursos são dedicados ao campo da Administração, e não foi identificada nenhuma oferta de formação a distância na área de Design

As instituições California College of the Arts; Burg Giebichenstein University of Art and Design e Royal College of Art (RCA) não ofertam cursos na modalidade a distância. Já a The Oslo School of Architecture and Design (AHO), situada na Noruega, oferece cursos de curta duração e disciplinas eletivas a distância utilizando a plataforma Moodle, cujo endereço do AVA é $<$ http://Ims.aho.no/Moodle/>. Tais cursos estão no âmbito do Design.

A University for the Creative Arts utiliza a plataforma Blackboard para a oferta de cursos nas áreas de desenho, fotografia, ilustração, design gráfico, escrita criativa, têxteis, escultura, gravura e história da arte. E a instituição Emily Carr University of Art and Design usa a plataforma Moodle.

Em síntese, a partir da análise das 28 instituições, foi possível constatar que uma parte significativa não oferta cursos ou disciplinas de Design na modalidade a distância. Aquelas que ofertam cursos online, em geral, utilizam ambientes virtuais Moodle ou Blackboard. Apresentamos a seguir um quadro-síntese com o objetivo de explicitar quais ambientes virtuais de aprendizagem são utilizados pelas instituições classificadas pelo Red Dot Design.

Quadro 2 - Instituições que oferecem cursos de Design a distância e seu respectivo Ambiente Virtual de Aprendizagem

\begin{tabular}{ll}
\hline Instituição & AVAs em cursos de Design \\
\hline Savannah College of Art and Design & Blackboard \\
\hline Academy of Art University & Whiteboard \\
\hline Middle East Technical University (METU) & Moodle \\
\hline
\end{tabular}




\begin{tabular}{ll}
\hline Instituição & AVAs em cursos de Design \\
\hline California College of the Arts & Moodle \\
\hline The Oslo School of Architecture and Design (AHO) & Moodle \\
\hline University for the Creative Arts & Blackboard \\
\hline Emily Carr University of Art and Design & Moodle \\
\hline Central Saint Martins College of Art \& Design & Moodle
\end{tabular}

Fonte: Elaborado pelos autores.

Observamos em nosso levantamento que a instituição Academy of Art University é a única que afirma ter desenvolvido um ambiente próprio, intitulado Whiteboard, para a oferta de disciplinas e cursos no campo do Design. Essa constatação pode ser observada na apresentação e definição do ambiente, disponível no website da Universidade:

\begin{abstract}
Desenvolvemos nosso próprio Sistema de Gerenciamento de Aprendizagem personalizado - uma ferramenta web que permite aos estudantes e professores interagirem e trocarem facilmente recursos digitais. O recurso Whiteboard permite aos tutores agendar a entrega de trabalhos e fornecer feedback detalhado, incluindo comentários de áudio. O Sistema de Gerenciamento de Aprendizagem Whiteboard também serve como um canal centralizado para notícias e atualizações de classe, informações de notas, suporte, agendamento de sessões de tutoria individuais e uma série de outros recursos adaptados para tornar sua educação online tão rica quanto possível. (ACADEMYART, 2017)
\end{abstract}

No Quadro 3, temos a exposição dos Ambientes Virtuais de Aprendizagem utilizados por instituições qualificadas pelo ranking Red Dot Design, 2014 a 2017. No entanto, os AVAs são usados em cursos e disciplinas fora da área do Design.

Quadro 3 - Instituições no Red Dot Design (2014 a 2017) que oferecem cursos a distância fora da área do Design e seu respectivo Ambiente Virtual de Aprendizagem

\begin{tabular}{|c|c|}
\hline Instituição & $\begin{array}{l}\text { AVAs em outros cursos } \\
\text { (Não de Design) }\end{array}$ \\
\hline Umeå University & Moodle e Cambro \\
\hline Savannah College of Art and Design & Blackboard \\
\hline Academy of Art University & Whiteboard \\
\hline Middle East Technical University (METU) & Moodle /ODTUClass \\
\hline California College of the Arts & Moodle \\
\hline The Oslo School of Architecture and Design (AHO) & Moodle \\
\hline Pontifical Catholic University of Rio de Janeiro & Moodle \\
\hline University of Montreal & Moodle \\
\hline Central Saint Martins College of Art \& Design & Moodle \\
\hline Massachusetts Institute of Technology & Stellar / EDX \\
\hline Rhode Island School of Design (RSID) & Moodle \\
\hline Tomas Bata University in Zlín (TBU) & Moodle \\
\hline
\end{tabular}




\begin{tabular}{ll} 
Instituição & $\begin{array}{l}\text { AVAs em outros cursos } \\
\text { (Não de Design) }\end{array}$ \\
\hline Darmstadt University of Applied Sciences (H_DA) & Moodle \\
\hline University of Applied Sciences Northwestern Switzerland & Moodle \\
\hline Folkwang University of the Arts & Moodle \\
\hline Coventry University & Moodle \\
\hline University of Houston & Blackboard \\
\hline
\end{tabular}

Fonte: Elaborado pelos autores.

O Quadro 3 demonstra a prevalência do ambiente Moodle na oferta de cursos a distância, fora da área do Design, assim como constatado no Quadro 2 na oferta de cursos de Design. No entanto, diante dessa constatação, também se observa que a Instituição Umeå University utiliza, além do Moodle, o Ambiente Virtual de Aprendizagem intitulado Cambro, desenvolvido pela Universidade. Também desperta nossa atenção o fato de a Instituição Middle East Technical University (METU) construir um ambiente próprio a partir da configuração e customização estrutural da plataforma Moodle, intitulando-o ODTUClass.

\subsection{Ambientes Virtuais de Aprendizagem e a classificação QS World University}

Após o levantamento e análise dos ambientes utilizados pelas instituições classificadas pelo Red Dot Design, passamos a usar outra classificação internacional para verificar um número maior de universidades. Adotamos o ranking QS World University para verificar os AVAs utilizados por instituições de ensino superior mais bem posicionadas na relação.

O Qs World University Rankings são classificações universitárias publicadas anualmente sob a coordenação da empresa de consultoria Quacquarelli Symonds (QS), sediada na Inglaterra.

Para esta pesquisa, utilizamos uma compilação de classificação das edições dos anos de 2014 a 2018. A partir dessa compilação, elaboramos uma relação com 40 instituições, conforme segue:

Massachusetts Institute of Technology (MIT) / Stanford University / Harvard University / California Institute of Technology (Caltech) / University of Cambridge / University of Oxford / UCL (University College London) / Imperial College London / University of Chicago / ETH Zurich / Nanyang Technological University (NTU) / Ecole Polytechnique Fédérale de Lausanne / Princeton University / Cornell University / National University of Singapore (NUS) / Yale University / Johns Hopkins University / Columbia University / University of Pennsylvania / Australian National University / University of Michigan / Duke University / University of Edinburgh / King's College London (KCL) / University of Hong Kong / University of California, Los Angeles (UCLA) / University of Tokyo / Northwestern University / Hong Kong University of Science and Technology / University of Toronto / McGill University / University of Manchester / Kyoto University / Seoul National University / University of California, Berkeley (UCB) / University of Melbourne / Ecole normale supérieure, Paris / University of Bristol / Ecole Polytechnique / University of Sydney.

Notou-se predominantemente que os cursos que utilizam AVAs são aqueles NÃO ligados ao ensino de Design. A análise também revelou, dominantemente, a evidência de Ambientes Virtuais de Aprendizagem caracterizados pelo alinhamento aos cursos reconhecidos como massivos, denominados MOOC (Cursos Online Abertos e Massivos / Massive Open Online Course). Os MOOCs 
têm como foco o livre acesso ao conhecimento e possuem a intenção de atingir um público amplo de educandos. Além disso, tais cursos priorizam objetivos quantitativos de formação inicial ou continuada.

Por meio deste levantamento foi possível observar que 31 instituições internacionais de ensino superior, de um total de 40, ofertam cursos de Design. Essa parcela corresponde a 77\% do total das instituições selecionadas conforme expõe o Gráfico 1:

Gráfico 1 - Gráfico setorial baseado nos dados da pesquisa

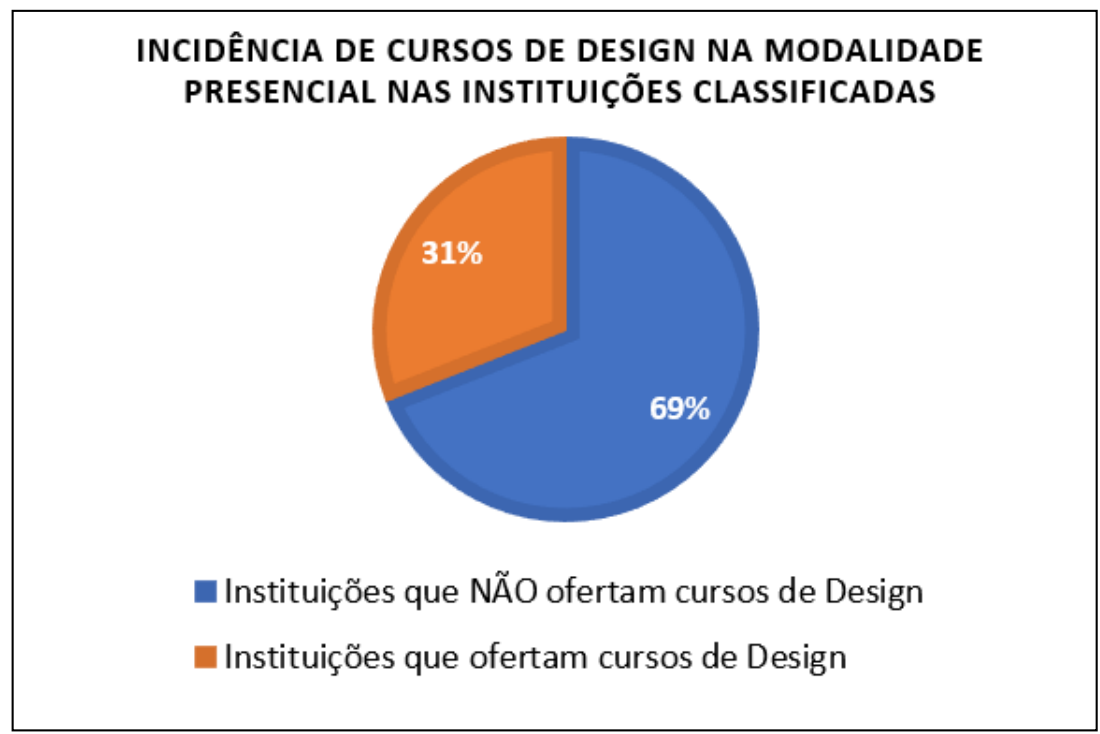

Fonte: Dados da Pesquisa.

A partir do levantamento e da análise das 40 instituições, revelou-se que em apenas quatro situações são utilizados Ambientes Virtuais de Aprendizagem em cursos de Design nas instituições classificadas pelo QS World University. Os ambientes virtuais utilizados são: EDX, ICE VLE, Coursera e Canvas para o ensino de Design na modalidade a distância, conforme aponta o Gráfico 2: 
Gráfico 2 - Gráfico setorial baseado nos dados da pesquisa

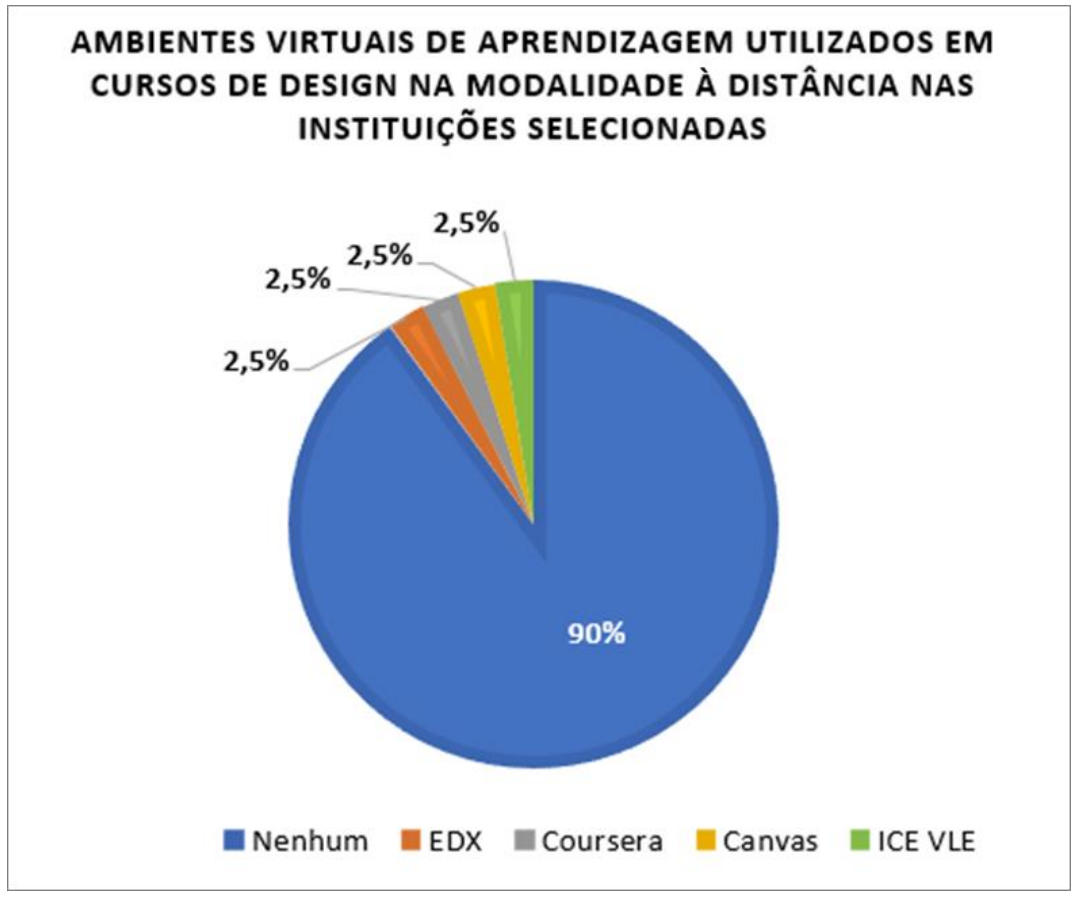

Fonte: Dados da Pesquisa.

Por meio dessa análise também foi possível obter informações no tocante à apropriação de Ambientes Virtuais de Aprendizagem pelas instituições selecionadas na oferta de outros cursos, não sendo, neste caso, cursos de Design. Têm-se um quantitativo de 32 adesões em contraposição a apenas 8 que ainda não utilizam nenhum tipo de AVAs. Nas instituições que utilizam os AVAS em suas modalidades de ensino, o recurso que se revela mais comumente utilizado é o Coursera, com $33,3 \%$ de adesão, seguido pelo EDX, com 20,5\% de uso. Já os ambientes Blackboard e Moodle aparecem na quarta e terceira classificação com $17,8 \%$ e $12,8 \%$ de adesão, respectivamente.

Os resultados alcançados por meio deste estudo revelam que uma parcela significativa das instituições de ensino superior classificadas pelo QS World University opta por utilizar AVAs com características do formato de cursos abertos e massivos, os chamados Massive Open Online Course (MOOC), conforme Gráfico 3: 
Gráfico 3 - Gráfico setorial baseado nos dados da pesquisa

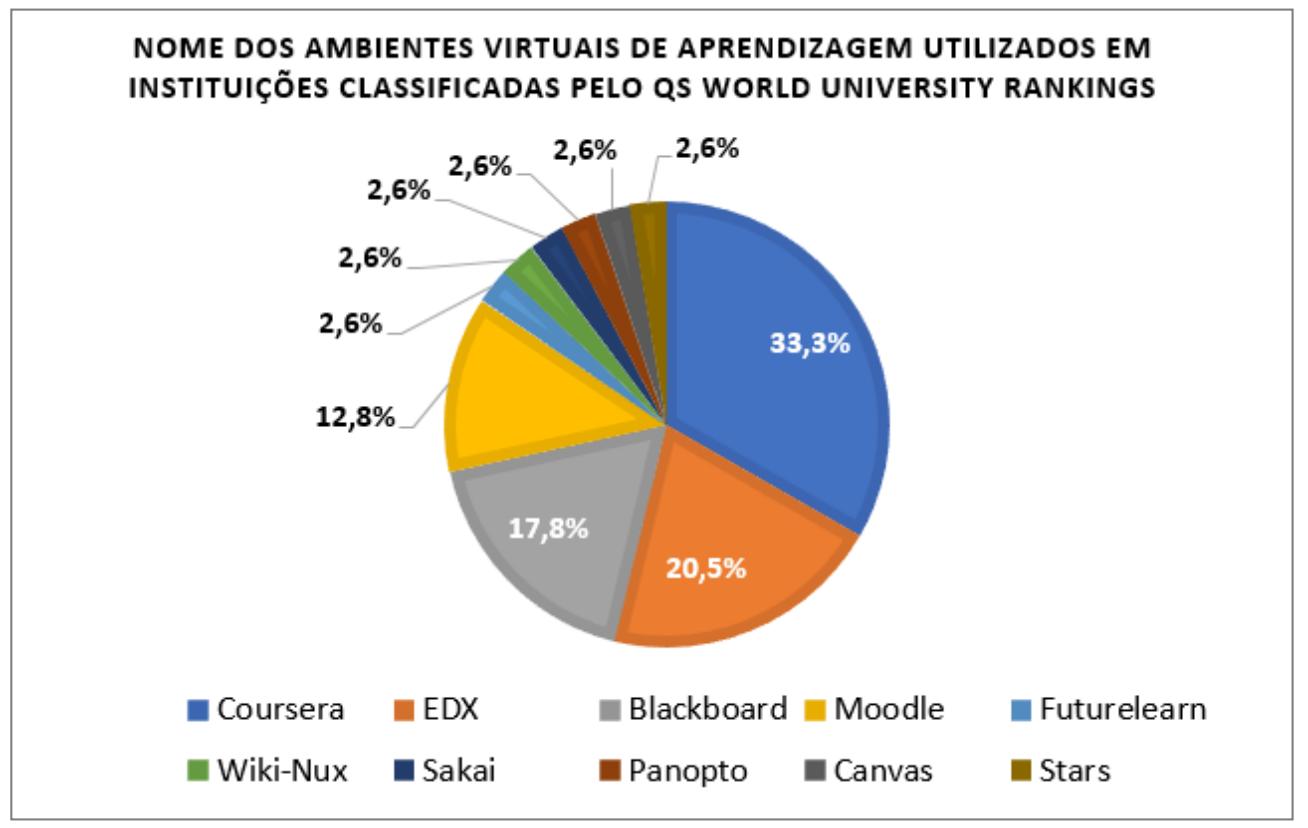

Fonte: Dados da Pesquisa.

A partir deste levantamento e exame das instituições de ensino, foi possível considerar o predomínio da utilização padronizada de AVAs construídos para o uso comum em cursos na modalidade a distância, revelando-se um número reduzido de iniciativas dedicadas na construção de novos ambientes em suas práticas educativas. Somada a essa realidade tem-se a constatação de que, embora os cursos de Design estejam presentes na maioria das instituições, são poucas propostas de confluências dos campos do Design e da Educação a distância no âmbito da construção de AVAs.

Considerando o levantamento e a análise das informações até aqui, é possível constatar a escassez de novos Ambientes Virtuais de Aprendizagem em instituições classificadas pelo Red Dot Design nas edições de 2014 a 2016 e pelo QS World University nas edições de 2014 a 2018. 


\section{Ambientes Virtuais de Aprendizagem mais utilizados internacionalmente}

Neste tópico, temos o intento de apresentar e analisar um panorama dos Ambientes Virtuais de Aprendizagem mais utilizados na atualidade, com o objetivo de também verificar a incidência de novos AVAs. Observa-se um contexto de ampliação de tecnologias digitais de informação e comunicação com a possibilidade de serem utilizadas na construção de recursos digitais e de AVAs. $\mathrm{Na}$ atualidade, o desenvolvimento e a expansão das tecnologias digitais de informação e comunicação têm propiciado a construção de diferentes recursos digitais educacionais, e, de modo especial, possibilitado o surgimento de novos Ambientes Virtuais de Aprendizagem. Como exemplo disso, além dos recursos EDX e Coursera criados no ano de 2012, há outras iniciativas, como o ambiente Edmodo, criado em 2007, que vem despontando no cenário educacional e ampliando o número de usuários mundialmente.

Diferentes proposições têm surgido de construção de ambientes dedicados tanto à Educação a Distância quanto á aprendizagem semipresencial, também conhecida como modalidade híbrida, numa aproximação entre a educação presencial e a distância. A modalidade de ensino híbrido tem origem na expressão inglesa "Blended Learning", comumente compreendido também como ensino semipresencial. A palavra "Blend" significa combinar, misturar. E, assim, esse formato de ensino preconiza a combinação entre a educação presencial com a educação a distância.

Assistimos na atualidade ao surgimento de diferentes AVAs que são utilizados não somente na Educação a Distância; percebemos iniciativas que tendem a utilizar os AVAs como um recurso de apoio ao ensino presencial.

Sendo assim, buscamos também identificar e analisar os AVAs mais utilizados no ensino a distância, a partir de um levantamento de ambientes mais utilizados internacionalmente. A classificação apresentada a seguir assumiu os critérios de categorização promovida pela equipe do Capterra. O Capterra é um diretório online que classifica diferentes softwares adotando critérios como quantidade de usuários, vínculo em redes sociais, números de consumidores, entre outros.

Figura 1 - Gráfico setorial com nomes dos Ambientes Virtuais de Aprendizagem mais utilizados internacionalmente com quantitativo de usuários

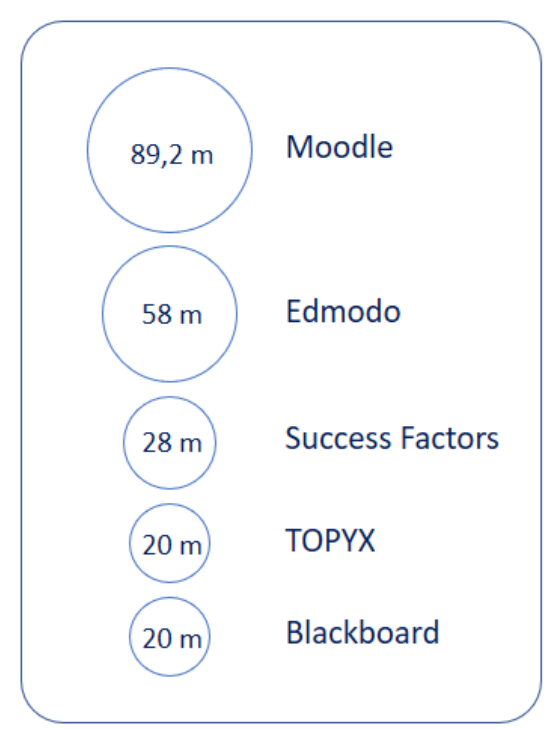

Fonte: Capterra (2016) 
A Figura 1 demonstra o quantitativo de usuários em diferentes Ambientes Virtuais de Aprendizagem, contabilizados no ano de 2016. Nota-se a partir desse panorama que os Ambientes Virtuais de Aprendizagem mais utilizados em propostas de Educação a distância são, respectivamente, Moodle, Edmodo, Success Factors, TOPYX e Blackboard. Os números demonstram que os ambientes Moodle e Edmodo possuem juntos uma quantidade de usuários superior ao dobro das três plataformas na sequência. A Figura 1 também revela a presença de um número expressivo de usuários diante das diferentes propostas de AVAs já construídos.

\section{Análise e discussão dos Ambientes Virtuais de Aprendizagem mais usados internacionalmente}

A partir do levantamento de AVAs utilizados, é possível tecer algumas reflexões no que se refere às características e possibilidades de tais recursos. É possível, por exemplo, reconhecer elementos típicos nos ambientes virtuais de modo a identificar aspectos positivos disponíveis nos AVAs. Observam-se os ambientes Moodle, Blackboard, Coursera e EDX como os que mais se evidenciam em instituições voltadas para o Design, e o Edmodo como um dos AVAs mais utilizados internacionalmente, possibilitando, assim, estabelecer algumas reflexões.

Os ambientes Moodle e Blackboard são os AVAs que mais apresentam funcionalidades voltadas a situações de aprendizagem em uma concepção construtivista/interacionista. Tal constatação se deve pela multiplicidade de recursos disponíveis e pela variabilidade e flexibilidade na configuração do layout desses AVAs. Tais ambientes oferecem a possibilidade de organização e customização do espaço de interação, tanto na inserção de recursos e funcionalidades quanto na colocação das atividades dos cursos.

Já os ambientes Edmodo, EDX e Coursera são propostas mais rígidas no que se refere à configuração do layout. Contudo, o Edmodo destaca-se dos demais por dispor de uma interface gráfica simples que propicia certa facilidade para aprender a utilizá-lo de modo prático para tutores e educandos-usuários. De modo particular, no Edmodo há uma facilidade em utilizá-lo por este apresentar uma interface similar àquelas das redes sociais digitais. $\mathrm{O}$ ambiente é análogo às redes sociais e dispõe de um mural de postagens num formato de Linha do Tempo (Timeline), favorecendo ações de compartilhamento, comentários e curtidas das publicações de tutores e educandos

\section{Considerações parciais dos Ambientes Virtuais de Aprendizagem}

Nesta pesquisa foi possível constatar que as instituições classificadas pelo Red Dot Design e pelo QS World University optam pelo uso de Ambientes Virtuais de Aprendizagem comumente reconhecidos, revelando uma escassez de alternativas na produção e apropriação de novos AVAs. O levantamento também pôde demonstrar que as opções mais adotadas pelas instituições envolvidas com o ensino de Design são, respectivamente, os ambientes Moodle e Blackboard, na classificação Red Dot Design; e os ambientes EDX e Coursera, na classificação QS World University, evidenciando, assim, uma escassez de construções de novos AVAs por instituições que ofertam cursos de Design.

Os ambientes EDX e Coursera, embora apresentem características de democratização do acesso ao conhecimento, também demonstram um viés caracterizado pela concepção de formação 
massiva, seguindo critérios com níveis de configuração nos ambientes de modo restrito. Já os ambientes Moodle e Blackboard, por apresentarem uma grande diversidade de funções, tendem a demandar do usuário um aprendizado mais detalhado para seu uso.

O estudo também revelou ser um ponto positivo os AVAs apresentarem certa flexibilidade na configuração de sua interface, permitindo aos usuários adequá-los às suas necessidades, como no caso do Moodle e Blackboard. Além disso, considera-se relevante disponibilizar uma quantidade moderada de funcionalidades e recursos educativos, com o objetivo de possibilitar uma facilidade na configuração e no uso.

Também é adequado que o ambiente apresente certa simplicidade de utilização com um layout simples, amigável, como no exemplo do Edmodo. Defende-se a aproximação interdisciplinar entre os campos do Design e da EaD com vistas a otimizar estratégias de concepção e produção de AVAs favoráveis aos processos de ensino-aprendizagem.

No entanto, o ponto de maior relevância que destacamos com este levantamento é que foi possível identificar, a partir dessa análise do panorama atual, um grau de isolamento entre o Design e a Educação a distância na proposição da diversidade de construção de novos AVAs. Tínhamos como pressuposto que instituições envolvidas com o ensino de Design teriam a oportunidade de dedicar-se amplamente na produção de AVAs seguindo critérios otimizados de interação entre educandos, educadores e AVAs. Contudo, o levantamento demonstrou, de modo geral, que tais instituições optam pelo uso de recursos comumente reconhecidos, revelando uma escassez de alternativas na produção e apropriação de novos AVAs. O levantamento também demonstrou que as opções mais adotadas pelas instituições envolvidas com o ensino de Design são, respectivamente, os ambientes Coursera, EDX, Blackboard e Moodle. Esses ambientes, embora apresentem características de democratização e popularização do acesso ao conhecimento e à formação superior, também demonstram um viés caracterizado pela formação massiva, seguindo critérios com níveis de configuração dos AVAs restritos.

Neste sentido, acreditamos que uma maior preocupação dos cursos de Design na formação de profissionais capacitados a desenvolver Ambientes Virtuais de Aprendizagem, possa não somente potencializar novas possibilidades de recursos que tenham como foco o ensinoaprendizagem, de uma maneira geral, e mais especificamente os cursos de Design, como também possam fomentar a utilização destes ambientes nos próprios cursos, ofertando diferentes oportunidades de ensino para os alunos de Design.

\section{Agradecimentos}

Agradecemos à Fundação de Amparo à Pesquisa do Estado de Minas Gerais (FAPEMIG) pelo apoio financeiro.

\section{Referências}

ACADEMYART. Online Education. Disponível em: <https://www.academyart.edu/onlineeducation/>. Acesso em: 03 nov. 2017.

CAPTERRA. LMS Software. Disponível em: <http://www.capterra.com/learning-management- 
system-software /\#infograpic>. Acesso em: 23 set. 2017.

COUTO, R. M. S. (Org.); OLIVEIRA, A. J. (Org.). Formas do Design: Por uma metodologia interdisciplinar. Rio de Janeiro: 2AB, 1999.

PEREIRA, A. T. C.; GONÇALVES, B. O Ambiente Virtual de Aprendizagem em Arquitetura e Design da UFSC: do projeto à realidade. In: VIII CONGRESSO IBERO-AMERICANO DE GRÁFICA DIGITAL - o sentido e o universo digital, 2004, São Leopoldo. Anais... São Leopoldo: Celso Carnos Scaletsky e Isabel Medero Rocha, 2004. p. 353-356.

PORTUGAL, Cristina. Design, Educação e Tecnologia. Rio de Janeiro: Rio Books, 2013.

RED DOT. Red Dot Design Ranking. Disponível em: <http://www.red-dot.sg/en/red-dot-designranking/>. Acesso em: 06 out. 2017. 